\title{
The effect of civil and military flights on coagulation, fibrinolysis and blood flow: insight from a rat model
}

Anna Levkovsky ${ }^{1,2+}$, Rima Dardik ${ }^{3 \dagger}$, Daniel Barazany ${ }^{4}$, David M. Steinberg ${ }^{5}$, Mark Dan Kirichenko ${ }^{4}$, Sara Apter ${ }^{6,7}$, Edna Peleg ${ }^{2,8}$, Daniel Silverberg ${ }^{2,9}$, Ehud Grossman ${ }^{2,10+}$ and Ophira Salomon ${ }^{1,2^{*+}}$ (D)

\begin{abstract}
Background: Air travel thrombosis continues to be a controversial topic. Exposure to hypoxia and hypobaric conditions during air travel is assumed a risk factor. The aim of this study is to explore changes in parameters of coagulation, fibrinolysis and blood flow in a rat model of exposure to hypobaric conditions that imitate commercial and combat flights.

Methods: Sixty Sprague-Dawley male rats, aged 10 weeks, were divided into 5 groups according to the type and duration of exposure to hypobaric conditions. The exposure conditions were $609 \mathrm{~m}$ and $7620 \mathrm{~m}$ for 2 and $12 \mathrm{~h}$ duration. Blood count, thrombin- antithrombin complex, D-dimer, interleukin-1 and interleukin- 6 were analyzed. All rats went through flight angiography MRI at day 13-post exposure.

Results: No effect of the various exposure conditions was observed on coagulation, fibrinolytic system, IL-1 or IL-6. MRI angiography showed blood flow reduction in lower limb to less than $30 \%$ in $50 \%$ of the rats. The reduction in blood flow was more pronounced in the left vessel than in the right vessel ( $p=0.006$, Wilcoxon signed rank test). The extent of occlusion differed across exposure groups in the right, but not the left vessel $(p=0.002, p=0.150$, respectively, Kruskal-Wallis test). However, these differences did not correlate with the exposure conditions.

Conclusion: In the present rat model, no clear correlation between various hypobaric conditions and activation of coagulation was observed. The reduction in blood flow in the lower limb also occurred in the control group and was not related to the type of exposure.
\end{abstract}

Keywords: D-dimer, Hypobaric conditions, IL-6, MRI, Thrombin-antithrombin

\footnotetext{
* Correspondence: ophira.Salomon@sheba.health.gov.il

${ }^{\dagger}$ Anna Levkovsky, Rima Dardik, Ehud Grossman and Ophira Salomon

contributed equally to this work.

'Thrombosis Unit Sheba Medical Center, Coagulation Institute, 52621 Tel

Hashomer, Israel

${ }^{2}$ Sackler Faculty of Medicine, Tel Aviv University, Tel Aviv, Israel

Full list of author information is available at the end of the article
}

(c) The Author(s). 2020 Open Access This article is licensed under a Creative Commons Attribution 4.0 International License, which permits use, sharing, adaptation, distribution and reproduction in any medium or format, as long as you give appropriate credit to the original author(s) and the source, provide a link to the Creative Commons licence, and indicate if changes were made. The images or other third party material in this article are included in the article's Creative Commons licence, unless indicated otherwise in a credit line to the material. If material is not included in the article's Creative Commons licence and your intended use is not permitted by statutory regulation or exceeds the permitted use, you will need to obtain permission directly from the copyright holder. To view a copy of this licence, visit http://creativecommons.org/licenses/by/4.0/ The Creative Commons Public Domain Dedication waiver (http://creativecommons.org/publicdomain/zero/1.0/) applies to the data made available in this article, unless otherwise stated in a credit line to the data. 


\section{Introduction}

Air travel thrombosis is a subgroup of thrombosis that occurs within 4 weeks following long haul air travel [1]. Exposure to hypoxia and hypobaric conditions during air travel are considered as risk factors, alongside immobilization, which is common to all land travel thrombosis cases [1-4].

Commercial airplanes usually fly at about $10,800 \mathrm{~m}$ $(35,433 \mathrm{ft})$ above sea level, while compressing air to about $75.8 \mathrm{kPa}(570 \mathrm{mmHg})$, which is essential to prevent hypoxia because of reduced barometric pressure at such an altitude. The cabin's pressure is kept equivalent to an altitude of $1500-2500 \mathrm{~m}$ with partial oxygen pressure of $16.7 \mathrm{kPa}(125 \mathrm{mmHg})$. Oxygen saturation is reduced to $90-93 \%$ in healthy individuals, but it may drop even to $80 \%$ during the flight in patients with pulmonary and/or heart disease.

Combat aircraft may operate at altitudes of $7620 \mathrm{~m}$ $(25,000 \mathrm{ft})$ and even more [5], and the grade of air pressurization is dependent on the altitude $[3,5,6]$.

The phenomenon of air travel thrombosis as a concept continues to be a controversial topic since most studies were conducted on few participants with heterogeneous clinical characteristics, type of exposure and duration, with no pre- and post-exposure comparison of coagulation parameters and lack of a control group [3, 7]. Furthermore, there was inconsistency concerning the activation of coagulation and fibrinolytic pathways when fragment $1+2$, thrombin-antithrombin (TAT) complex and D-dimers were measured [3, 7-10].

The incidence of deep vein thrombosis (DVT) in low risk travelers was $1.6 \%$ compared to $5 \%$ in those with additional risk factors [11, 12].

Concerning hypobaric conditions, there was a transient activation of coagulation factors in volunteers held in a hypobaric chamber [13]. In rabbits, the risk of DVT was augmented by exposure to hypobaric conditions following surgery of the femur, as compared to rabbits that were not exposed to a postoperative drop in air pressure [14].

Hypoxia has been demonstrated to decrease fibrinolytic activity and incite the formation of oxygen free radicals and nitric oxide by endothelial cells [7]. The latter causes relaxation of the venous vessels with decreased blood flow velocity and stasis, which may promote venous thromboembolism.

Direct evidence that would support or exclude the association between air travel and thrombosis would require a large number of participants due to the low incidence of air-travel thrombosis, and it is unlikely that airline companies or funding agencies would sponsor such studies.

Therefore, in this study we used a rat model of exposure to hypobaric conditions compatible with conditions present during commercial and combat flights to explore changes that may occur in the coagulation, fibrinolysis and blood flow.

\section{Materials and methods \\ Animals}

Sprague-Dawley male rats were purchased from Envigo RMS (Jerusalem, Israel) at the age of 10 weeks and weight $340-405 \mathrm{~g}$. The rats were acclimated for 3 days before study initiation. Three rats per plastic cage were housed at a temperature of $22 \pm 2{ }^{\circ} \mathrm{C}$ in a controlled room with alternating 12-h light/dark cycle, with regular chow diet and water available ad libitum before and after the exposure experiment. During exposure to hypobaric conditions, smaller cages, housing two rats each, were needed to adjust to the cabin settings. The rats received regular diet but no water as the water bottles were not adjusted to the hypobaric conditions. The control rats were also deprived of water for $12 \mathrm{~h}$, which corresponded to their time of exposure. All rat procedures were carried out based on ethical approval and in accordance with The Animal Care and Use Committee of Sheba Medical Center, Tel-Hashomer (approval number 1046/16).

\section{Study design}

Groups of 12 rats each were assigned to the five groups defined by the type and duration of exposure to hypobaric conditions as shown in Table 1.

\section{Hypobaric exposure}

Rats were exposed to hypobaric conditions at the Israel Air Force Aeromedical Center's Hypobaric Training facility. The chamber, purchased from Vacudyne (Chicago, USA), was connected to a vacuum pump with controlled air inflow and outflow. The hypobaric conditions were launched by dropping the barometric pressure. The low altitude condition in the study was equivalent to $609 \mathrm{~m}$ and represents atmospheric pressure of $706 \mathrm{mmHg}$, and $148 \mathrm{mmHg}$ oxygen partial pressure (effective oxygen $19.4 \%$, by measurement). The high altitude condition was equivalent to $7620 \mathrm{~m}$ and represents atmospheric pressure of $282 \mathrm{mmHg}$ and $59 \mathrm{mmHg}$ oxygen partial pressure (effective oxygen $7.6 \%$, by measurement).

Table 1 Characteristic of rats' group according to type and duration of exposure to hypobaric conditions

\begin{tabular}{lll}
\hline Groups & Height & Duration of exposure \\
\hline 1 & $609 \mathrm{~m}(2,000 \mathrm{ft})$ & $2 \mathrm{~h}$ \\
2 & $609 \mathrm{~m}(2,000 \mathrm{ft})$ & $12 \mathrm{~h}$ \\
3 & $7620 \mathrm{~m}(25,000 \mathrm{ft})$ & $2 \mathrm{~h}$ \\
4 & $7620 \mathrm{~m}(25,000 \mathrm{ft})$ & $12 \mathrm{~h}$ \\
5 & Sea levels & $12 \mathrm{~h}$ \\
\hline
\end{tabular}




\section{Blood samples}

Three mL blood was drawn from the retro-orbital sinus of each rat and divided into 3 tubes with 10\% ethylenediaminetetraacetic acid (EDTA) following anesthesia (with $0.5 \mathrm{ml}$ isoflurane), at day 4 before exposure to hypobaric conditions, at day 6 immediately post exposure and at day 21 a day before MRI was done. Blood count was performed using Beckman Coulter DxH900 analyzer (Farminpex N. V, USA).

\section{Thrombin-Antithrombin (TAT) complex and D-dimer tests} Blood samples were centrifuged at $1000 \mathrm{x}$ g for $15 \mathrm{~min}$ at room temperature, followed by additional centrifugation of the plasma at 10,000 $\mathrm{x}$ g for $15 \mathrm{~min}$ at $4{ }^{\circ} \mathrm{C}$. Blood samples were processed within $1 \mathrm{~h}$ of blood withdrawal and stored at $-80^{\circ} \mathrm{C}$ until analysis at the end of the study. Rat enzyme-linked immunosorbent assay (ELISA) kit (Mybiosource company, San Diego, USA) and rat D-dimer (D2D) competitive ELISA kit (Mybiosource company) were used for analyzing TAT complex and D-dimer, respectively, according to the manufacturer's instructions.

\section{Cytokines}

Interleukin-1 (IL-1) and interleukin- 6 (IL-6) were analyzed by rat interleukin- $1 \beta$ and rat IL- 6 ELISA kit (Mybiosource company) according to the manufacturer's instructions.

\section{MRA screening}

All rats went through MRI angiography (MRA) scan at Strauss MRI Center, Tel Aviv University, 13 days after hypobaric exposure using a $7 \mathrm{~T} / 30$ Bruker Biospec scanner with a $72 \mathrm{~mm}$ cylinder transmit-receive coil. The rats were placed in prone position in the scanner with the back limbs secured by tape. Anesthesia was maintained with isoflurane $\left(2-3 \%\right.$ in pure $\left.\mathrm{O}_{2}\right)$ and body temperature was kept at $38.5^{\circ} \mathrm{C}$ by a heating pad during imaging. We used 2-dimensional Time of Flight (2D-TOF) angiography through $\mathrm{TR} / \mathrm{TE}=20 \mathrm{~ms} / 2.25 \mathrm{~ms}$, flip angle was $80^{\circ}, 39$ coronal slices of $1 \mathrm{~mm}$ with an in-plane resolution of $0.275 \mathrm{~mm} 2$ in a scan time of $7 \mathrm{~min}$ and $30 \mathrm{~s}$. The 2D-TOF MRA images were acquired perpendicular to the orientation of the vessels' blood flow.

\section{MRA score}

TOF MRA produces an enhanced signal intensity stemming from flow of unsaturated blood into saturated area. The acquired signal intensity is correlated to the degree of blood, hence, TOF MRA technique is mostly used to demonstrate blood flow qualitatively. To quantify the flow reduction, the TOF signal intensity was standardized by division by a reference flow. The minimal standardized flow was recorded as an MRA score to measure and compare occlusion for both the right and left blood vessels.

\section{Statistical methods}

Data are summarized for all animals by mean values. Comparisons were performed using non-parametric statistical tests. Comparisons across groups were performed using the Kruskal-Wallis test and comparisons for paired data were performed using the Wilcoxon signed rank test. Pearson correlations were used to describe relationships between numerical variables.

\section{Results}

\section{Clinical characteristics of the rats}

Sixty rats were included in the study. Four rats died during exposure as follows: one rat following exposure to $609 \mathrm{~m}$ for $2 \mathrm{~h}$ and 3 rats following exposure to $7620 \mathrm{~m}$ for $12 \mathrm{~h}$. One rat died immediately after exposure to $7620 \mathrm{~m}$ for $2 \mathrm{~h}$ and one control group rat died just before MRI. There was a consistent decrease in weight immediately following exposure to hypobaric conditions, with significant differences by group $(p<0.00001$, Kruskal-Wallis test). The largest reduction, approximately $20 \mathrm{~g}$ on average, occurred in rats that were exposed for $12 \mathrm{~h}$ to hypobaric conditions. Weight returned to pre-exposure levels when measured 13 days later.

\section{Blood counts}

There were reductions in both hematocrit and hemoglobin. The reduction in hematocrit differed significantly among the groups $(p=0.00016$, Kruskal-Wallis test), with the largest reduction observed in rats exposed to $609 \mathrm{~m}$ and $7620 \mathrm{~m}$ for $2 \mathrm{~h}$ as shown in Fig. 1a. There was a weak negative correlation between the change in weight and the change in hematocrit $(r=-0.27)$. The number of platelets increased in $69 \%$ of the rats following exposure, with an average increase of $138.3 \mathrm{k} / \mu \mathrm{L}$. There were no significant differences among the groups $(p=0.32$, Kruskal-Wallis test) as seen in Fig. 1b.

\section{TAT and D-dimer}

The analysis of TAT complex revealed that five rats were positive at the time of acclimation before exposure to hypobaric conditions (mean $\pm \mathrm{SD}$ for positive rats: $3020 \pm 1692 \mathrm{pg} / \mathrm{mL}$ ). Following exposure, TAT complex levels were elevated in 8 rats, 4 of which belonged to the control group. No differences in the level of TAT complex were observed between rats exposed to hypobaric conditions and the control group rats (mean \pm SD for positive rats: $4900 \pm 2125 \mathrm{pg} / \mathrm{mL}$ and $4875 \pm 3147 \mathrm{pg} / \mathrm{mL}$ for control and hypobaric exposure groups, respectively). At 16 days, TAT complexes were elevated in 7 rats: two were exposed to $609 \mathrm{~m}$ for $2 \mathrm{~h}$ (mean \pm SD: $6100 \pm 2187$ $\mathrm{pg} / \mathrm{mL}$ ), 4 were exposed to $609 \mathrm{~m}$ for $12 \mathrm{~h}$ (mean $\pm \mathrm{SD}$ : 
a.

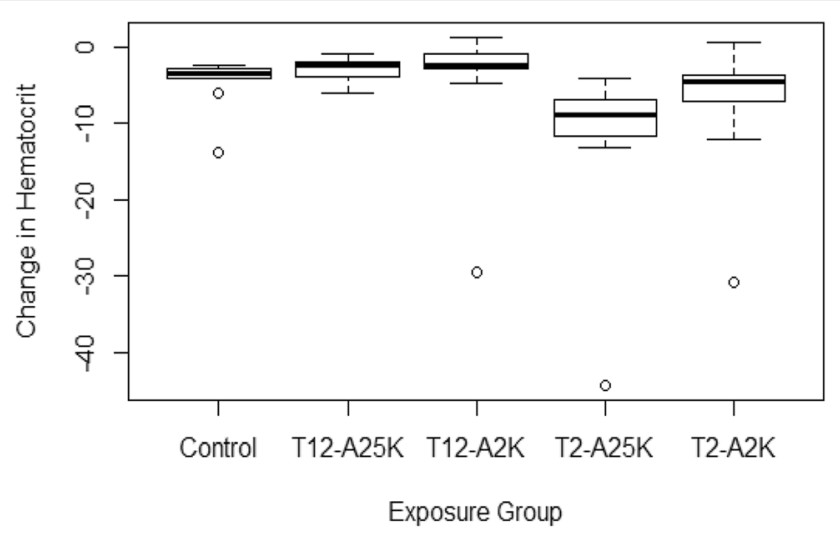

b.

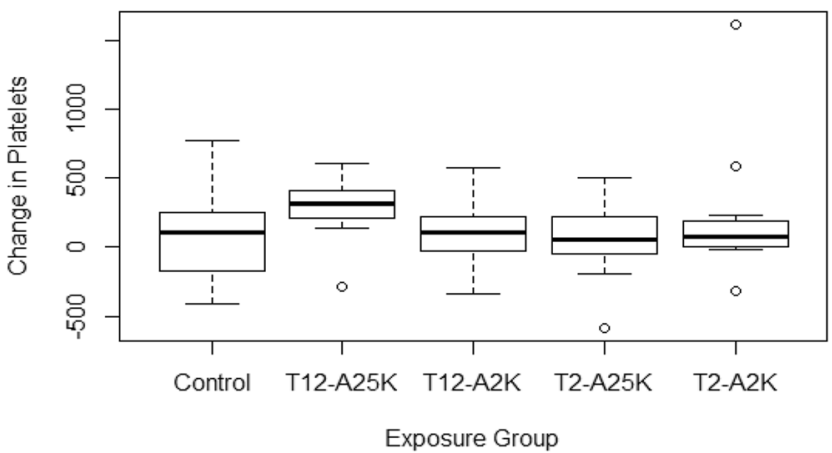

Fig. 1 The level of hematocrit (a) and platelets (b) during acclimation, following exposure to hypobaric conditions and 13 days later according to various hypobaric conditions. $T=$ exposure's time, $\mathrm{A}=$ altitude

$5625 \pm 5648 \mathrm{pg} / \mathrm{mL}$ ) and 1 rat was exposed to $7620 \mathrm{~m}$ for $2 \mathrm{~h}(3000 \mathrm{pg} / \mathrm{mL})$. Dot plots of TAT levels at various exposure conditions are presented in supplemental Fig. 1.

$\mathrm{D}$-dimer was negative in all rats during acclimation. Following hypobaric exposure slightly elevated D-dimer levels were observed at 16 days in only two rats $(4 \mathrm{ng} / \mathrm{ml}$ [609 $\mathrm{m}$ for $2 \mathrm{~h}$ ]; $8 \mathrm{ng} / \mathrm{ml}$ [609 $\mathrm{m}$ for $12 \mathrm{~h}$ ]), both of which were negative for TAT complex at all 3 measurements.

\section{Cytokines: IL-1 and IL-6 levels}

The decrease in weight and hematocrit led us to measure IL-1 and IL-6, as both cytokines are known to be involved in inflammation and thrombosis. In 6 rats, the IL-1 levels were already high at the time of acclimation (mean \pm SD: $70 \pm 46.5 \mathrm{pg} / \mathrm{mL}$ ). Following exposure, IL-1 was $40 \mathrm{pg} / \mathrm{mL}$ in one rat and $80 \mathrm{pg} / \mathrm{mL}$ in another one. At the end of the experiment, IL-1 increased in only 2 rats, with levels of $40 \mathrm{pg} / \mathrm{mL}$ each.

Elevated IL- 6 was found in 4 rats during acclimation (mean \pm SD: $238 \pm 180 \mathrm{pg} / \mathrm{mL}$ ). After exposure, IL-6 increased in 3 rats exposed to $609 \mathrm{~m}$ for $2 \mathrm{~h}$ (mean \pm SD: $154 \pm 87 \mathrm{pg} / \mathrm{mL})$, in one rat exposed for $12 \mathrm{~h}(500 \mathrm{pg} /$ $\mathrm{mL}$ ) and in 2 control rats ( 300 and $400 \mathrm{pg} / \mathrm{mL}$ ). At 16 days, IL-6 was elevated in 5 rats, 2 of which were control rats (range $150-400 \mathrm{pg} / \mathrm{mL}$ ).
Taken together, the increment of IL- 1 and IL- 6 was not related to mode of exposure or time post-exposure.

MRA

MRA was performed in 54 rats, but could be evaluated in only 52 rats. Figure 2 presents an MRA taken from a representative rat with minimal blood flow in the

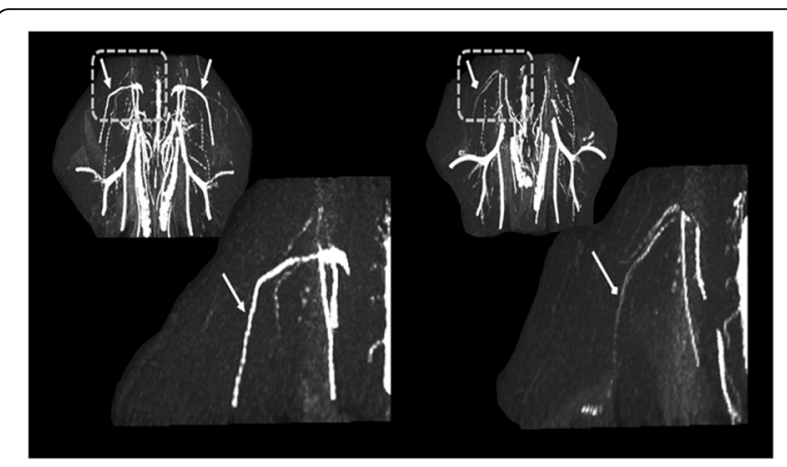

Fig. 2 2D-TOF MRI angiography images of the rat's abdomen area in the coronal view. Two representative rats $(\mathrm{N} 1, \mathrm{~N} 4)$ with intact and minimal blood flow are given (left and right respectively), with enlargement focusing on the left femoral veins (white arrows). Note the reduction of blood flow in bilateral femoral veins bilaterally, but with different severity 


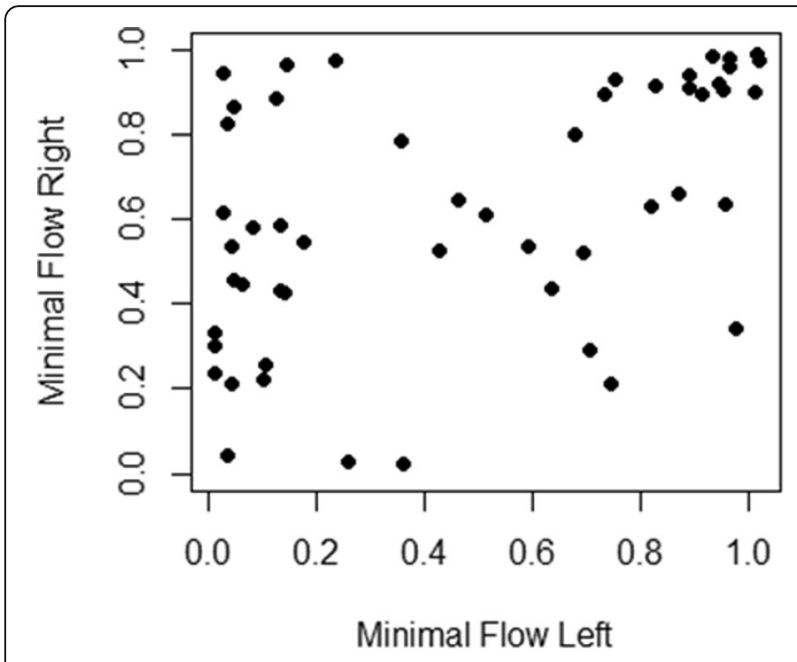

Fig. 3 Plot of minimum blood flow (as a fraction of reference flow) in the right vs. the left femur. The line is $y=x$. Most points are above the line indicating more obstruction in the left vessel. There is a modest positive correlation between the two femurs $(r=0.48)$. Animals with strong reduction in blood flow in the left femur often have little or no reduction in the right femur

femoral veins (white arrows) alongside a healthy rat with intact blood flow.

Note that the flow deficiency was observed in both right and left femoral veins, but with different severity. Figure 3 shows the modest correlation between minimal flow in the right versus left femoral vein $(r=0.48)$.

Greater flow reduction was observed in the left vessel in $65 \%$ of the rats. The median difference of the right vs left flow reduction scores was 0.11 and the differences were statistically different from $0(p=0.006$, Wilcoxon signed rank test).

There were significant differences by exposure group for reduced flow in the right vessel, but not in the left vessel ( $p=0.002, p=0.150$, respectively, Kruskal-Wallis test). The extent of flow reduction did not show any correlation with the exposure conditions. For the right vessel, the lowest median values were 0.36 (for the group exposed for $2 \mathrm{~h}$ at $609 \mathrm{~m}$ ) and $0.46(12 \mathrm{~h}$ at 7620 $\mathrm{m})$. The median values for the other groups were 0.75 $(12 \mathrm{~h}$ at $609 \mathrm{~m}), 0.87(2 \mathrm{~h}$ at $7620 \mathrm{~m})$ and 0.90 (control). The left vessel had larger flow reductions; the lowest median values were $0.13(12 \mathrm{~h}$ at $7620 \mathrm{~m}), 0.14(2 \mathrm{~h}$ at $609 \mathrm{~m}$ ) and 0.28 (control). The median values for the other groups were $0.69(2 \mathrm{~h}$ at $7620 \mathrm{~m})$ and $0.82(12 \mathrm{~h}$ at $609 \mathrm{~m}$ ).

Half of the rats (26/52) had serious blood flow reduction to 0.3 or less in at least one of the two femoral veins. By group, these fractions ranged from $27 \%(3 / 11)$ in the $2 \mathrm{~h}, 7620 \mathrm{~m}$ group to $80 \%(8 / 10)$ in the $2 \mathrm{~h}, 609 \mathrm{~m}$ group, with $50 \%(5 / 10)$ in the control group.

\section{Discussion}

In this study of a rat model of exposure to different hypobaric conditions and duration, designed to mimic the conditions prevailing during civil flights or military aircraft missions, we found no laboratory indications for the activation of coagulation and fibrinolytic systems. Indeed, the amount of thrombin generated, which is often assessed by TAT complex, and the fibrinolytic system activity, which is reflected by increased D- dimer levels, were not elevated in most animals immediately following exposure or 13 days later.

In fact, when D-dimer was measured in cockpit crews who fly multiple short duration flights to rule out subclinical thrombotic events, there was no evidence for an increase [15]. Others assumed that the failure to detect raised concentration of $\mathrm{D}$-dimer in passengers with positive ultrasound scans is related to the short half-life (about $6 \mathrm{~h}$ ) of D-dimer and the long delay (up to $48 \mathrm{~h}$ ) before blood was sampled upon return from travel [16]. Therefore, in our project, we withdrew blood immediately post exposure and after 13 days, taking into account the fact that the risk of DVT tends to increase in the first 2 weeks following the flight $[4,11]$.

Additionally, we found reductions in hemoglobin and hematocrit, despite the fact that the rats were water deprived. Similar observations were noticed in 20 volunteers after transatlantic flight, where hemoglobin decreased without signs of dehydration [7].

A significant weight loss was observed in rats immediately post-exposure, with weight regained when analyzed 13 days later. The loss of weight following hypobaric exposure is attributed to muscle atrophy caused by increased protein degradation rate through up regulation of the ubiquitin-proteasome pathway [17]. This mechanism cannot explain the regained weight we observed in our rat model at day 13-post exposure or the decrease in weight in the control group. This fact led us to assess IL-1 and IL-6, both inflammatory cytokines that may be involved in thrombosis, besides being involved in the regulation of body fat $[18,19]$.

The level of IL-1 and IL-6 increased post-exposure in a small number of rats, but it was not related to exposure conditions.

We speculated that by using a $7 \mathrm{~T} / 30 \mathrm{MRA}$, we might reach higher diagnostic accuracy for detecting vessel occlusion in rats at 13 days post exposure. A significant reduction of blood flow to less than $30 \%$ in 26 rats (50\%) was observed in the femoral vein. These reductions were not related to exposure conditions.

Furthermore, we compared the blood flow between the right and left side of the lower limbs in all the rats and in relation to their group to rule out some slowdown of the flow that may indicate the likelihood of imminent clot formation. Occlusion of the left femoral 
vein was significantly greater than that of the right. Occlusion only of the right vessel achieved statistically significant differences across groups, but the extent of occlusion in that vessel was again unrelated to the exposure conditions.

We realize that our rat model cannot replace a human being, but we found that the aircraft cabin environment with hypobaric conditions did not promote vessel occlusion. This may explain why the incidence of DVT in pilots is not increased, even if they fly more frequently than most passengers [20].

We are aware of the fact that we did not have realtime measurements of partial oxygen pressure during exposure to of $609 \mathrm{~m}$ and $7620 \mathrm{~m}$, but used estimated pressures corresponding to the altitudes, reaching 19.4 and $7.6 \%$ respectively.

Since the coagulation and fibrinolysis pathways were not found to be activated, the degree of hypoxia should not alter our results.

\section{Conclusion}

In summary, our rat model points out that in hypobaric conditions simulating civil and combat flights to a certain degree, there was no evidence of substantial activation of coagulation, fibrinolysis, increased inflammatory cytokines or alteration of blood flow correlated with the type of exposure.

\section{Supplementary information}

Supplementary information accompanies this paper at https://doi.org/10. 1186/s12959-020-00237-8.

Additional file 1: Supplementary Fig. 1. TAT levels in rats allocated to the control group (sea level, no hypobaric exposure) and various hypobaric exposure groups (609 m 2 h, 609 m 12 h, 7620 m 2 h, 7620 m

$12 \mathrm{~h}$ ). For selected individual rats, changes in TAT levels from baseline are illustrated by lines of different colors, with each color representing an individual rat examined at various time points: baseline, immediately post-exposure and 16 days post-exposure.

\section{Abbreviations}

TAT: thrombin-antithrombin; DVT: deep vein thrombosis; ELISA: enzymelinked immunosorbent assay; 2D-TOF: 2-dimensional Time of Flight; MRA: MRI angiography

\section{Acknowledgments}

The authors thank Mrs. Zehava Shabtay for expert assistance in handling the rats.

\section{Authors' contributions}

Anna Levkovsky - Performed the experiment. Rima Dardik - Performed the experiment and approved the final version to be submitted. Daniel Barazany - Performed the experiments and analyzed the data. David M. Steinberg Analyzed, interpreted the data and wrote the manuscript. Mark Dan Kirichenko - Performed the experiment. Sara Apter - Analyzed and interpreted the data. Edna Peleg - Performed the experiment. Daniel Silverberg - Analyzed the data. Ehud Grossman - Revised the manuscript critically for important intellectual content. Ophira Salomon - The conception and design of the study, analyzed and wrote the manuscript. The author(s) read and approved the final manuscript.

\section{Funding}

Supported by the Israeli Army Grant (IDF-Israel Defense Forces).

\section{Availability of data and materials}

All data generated or analysed during this study are included in this published article (and its supplementary information files).

Ethics approval and consent to participate

All rat procedures were carried out based on ethical approval and in accordance with The Animal Care and Use Committee of Sheba Medical Center, Tel-Hashomer (approval number 1046/16).

\section{Consent for publication}

All authors have no financial or personal relationships with other people or organizations that could inappropriately influence their work. The work described has not been published before; it is not under consideration for publication anywhere else; its publication has been approved by all coauthors

\section{Competing interests}

The authors declare that they have no competing interests.

\section{Author details}

${ }^{1}$ Thrombosis Unit Sheba Medical Center, Coagulation Institute, $52621 \mathrm{Tel}$ Hashomer, Israel. ${ }^{2}$ Sackler Faculty of Medicine, Tel Aviv University, Tel Aviv, Israel. ${ }^{3}$ National Hemophilia Center and Thrombosis Unit, Sheba Medical Center, Tel-Hashomer, Israel. ${ }^{4}$ Strauss Computational Neuroimaging Center, Tel Aviv University, Tel Aviv, Israel. ${ }^{5}$ Department of Statistics and Operations Research, Faculty of Exact Sciences, Tel Aviv University, Tel Aviv, Israel. ${ }^{6}$ Department of Diagnostic Imaging, Sheba Medical Center, Tel-Hashomer, Israel. ${ }^{7}$ Tel Aviv University, Tel Aviv, Israel. ${ }^{8}$ Hypertension Unit, Sheba Medical Center, Tel-Hashomer, Israel. ${ }^{9}$ Department of Vascular Surgery, Sheba Medical Center, Tel-Hashomer, Israel. ${ }^{10}$ Internal Medicine Department, Sheba Medical Center, Tel Hashomer, Israel.

Received: 2 June 2020 Accepted: 1 September 2020

Published online: 06 October 2020

\section{References}

1. Sandor T. Travel thrombosis: Pathomechanisms and clinical aspects. Pathophysiology. 2008;15:243-52

2. Toff WD, Jones Cl, Ford I, Pearse RJ, Watson HG, Watt SJ, et al. Effect of hypobaric hypoxia, simulating conditions during long-haul air travel, on coagulation, fibrinolysis, platelet function, and endothelial activation. JAMA. 2006;295:2251-61.

3. Kuipers S, Schreijer AJ, Cannegieter SC, Büller HR, Rosendaal FR, Middeldorp S. Travel and venous thrombosis: a systematic review. J Intern Med. 2007; 262:615-34

4. Brown HK, Simpson AJ, Murchison JT. The influence of meteorological variables on the development of deep venous thrombosis. Thromb Haemost. 2009:102:676-82

5. Cable GG. In-flight hypoxia incidents in military aircraft: causes and implications for training. Aviat Space Environ Med. 2003;74:169-72.

6. Keynan Y, Bitterman N, Bitterman H. Hypoxia-reoxygenation contributes to increased frequency of venous thromboembolism in air travelers. Med Hypotheses. 2006;66:165-8.

7. Schobersberger W, Fries D, Mittermayr M, Innerhofer P, Sumann G, Schobersberger $B$, et al. Changes of biochemical markers and functional tests for clot formation during long-haul flights. Thromb Res. 2002;108:19-24.

8. Boccalon H, Boneu B, Emmerich J, Thalamas C, Ruidavets JB. Long-haul flights do not activate hemostasis in young healthy men. J Thromb Haemost. 2005:3:1539-41.

9. Mannucci PM, Gringeri A, Peyvandi F, Di Paolantonio T, Mariani G. Shortterm exposure to high altitude causes coagulation activation and inhibits fibrinolysis. Thromb Haemost. 2002;87:342-3.

10. von Känel R, Mills PJ, Fainman C, Dimsdale JE. Effects of psychological stress and psychiatric disorders on blood coagulation and fibrinolysis: a biobehavioral pathway to coronary artery disease? Psychosom Med. 2001; 63:531-44. 
11. Aryal KR, Al-Khaffaf H. Venous thromboembolic complications following air travel: what's the quantitative risk? A literature review. Eur J Vasc Endovasc Surg. 2006;31:187-99.

12. Martinelli I, Taioli E, Battaglioli T, Podda GM, Passamonti SM, Pedotti P, et al. Risk of venous thromboembolism after air travel: interaction with thrombophilia and oral contraceptives. Arch Intern Med. 2003;163:2771-4.

13. Bendz B, Rostrup M, Sevre K, Andersen TO, Sandset PM. Association between acute hypobaric hypoxia and activation of coagulation in human beings. Lancet. 2000;356:1657-8.

14. Hoffmann R, Schimmer RC, Largiader F. Surgery and environmental influence as risk -factors for the development of deep vein thrombosis in animal experiments. Thromb Haemost. 1993;70:712-6.

15. Jacobson BF, Philippides M, Malherbe M, Becker P. Risk factors for deep vein thrombosis in short-haul cockpit crews: a prospective study. Aviat Space Environ Med. 2002:73:481-4.

16. Scurr JH, Machin SJ, Bailey-King S, Mackie IJ, McDonald S, Smith PD. Frequency and prevention of symptomless deep- vein thrombosis in longhaul flights: a randomised trial. Lancet. 2001;357:1485-9.

17. Chaudhary P, Suryakumar G, Prasad R, Singh SN, Ali S, llavazhagan G Chronic hypobaric hypoxia mediated skeletal muscle atrophy: role of ubiquitin- proteasome pathway and calpain. Mol Cell Biochem. 2012;364: $101-13$.

18. Chida D, Osaka T, Hashimoto O, Iwakura Y. Combined interleukin-6 and interleukin-1 deficiency causes obesity in young mice. Diabetes. 2006;55 971-7.

19. Saghazadeh A, Rezaei N. Inflammation as a cause of venous thromboembolism. Crit Rev Oncol Hematol. 2016;99:272-85.

20. Johnston R, Evans A. Venous thromboembolic disease in pilots. Lancet. 2001;358:1734

\section{Publisher's Note}

Springer Nature remains neutral with regard to jurisdictional claims in published maps and institutional affiliations.

Ready to submit your research? Choose BMC and benefit from:

- fast, convenient online submission

- thorough peer review by experienced researchers in your field

- rapid publication on acceptance

- support for research data, including large and complex data types

- gold Open Access which fosters wider collaboration and increased citations

- maximum visibility for your research: over $100 \mathrm{M}$ website views per year

At $\mathrm{BMC}$, research is always in progress.

Learn more biomedcentral.com/submissions 